\title{
BIOÉTICA, PANDEMIA E SAÚDE PÚBLICA: A RELAÇÃO ENTRE INTERESSES COLETIVOS E INTERESSES INDIVIDUAIS
}

\author{
BIOETHICS, PANDEMIC AND PUBLIC HEALTH: THE RELATIONSHIP \\ BETWEEN COLLECTIVE INTERESTS AND INDIVIDUAL INTERESTS
}

\section{Lorena Roas Ribeiro ${ }^{1}$}

RESUMO: Esta pesquisa tem como objetivo estudar os aspectos bioéticos relacionados ao isolamento social na pandemia e, sua implicância na atualidade entre os interesses coletivos e individuais. A presente pandemia do novo coronavírus tem gerado inúmeros questionamentos sobre aspectos técnicos, éticos, morais, legais e sociais envolvidos na tomada de decisão envolvendo as medidas sanitárias, adotadas pelo governo democrático. $\mathrm{O}$ uso da quarentena humana como ação emergencial de saúde no combate à síndrome respiratória aguda grave (SARS) no início do milênio marcou, significativamente, a saúde pública, abrindo um novo campo de discussões referentes aos limites entre a proteção da coletividade e a redução do direito à autonomia e liberdade de pessoas ou grupos dentro de uma sociedade. Paradoxalmente, dividiu a opinião de especialistas entre a eficácia do método e os aspectos legais e éticos envolvidos durante a sua aplicação. O presente trabalho pautarse-á na descrição e análise da quarentena humana, na perspectiva da bioética por meio de revisão bibliográfica, na descrição do seu uso na atualidade, nos possíveis riscos que esta medida representa à autonomia, liberdade e dignidade humana. Os aspectos bioéticos foram levantados na busca da justificativa para verificar a adequação ou não das decisões tomadas. É importante esclarecer que a bioética pode utilizar vários modelos para realizar esta reflexão, com destaque para quatro grandes referenciais teóricos: as virtudes, os princípios, os direitos e a alteridade. Sua definição e conceito foram destacados na pesquisa através dos pensamentos de Potter, assim como, a discussão sobre estado de exceção, a aplicabilidade da quarentena e a sobreposição dos interesses coletivos nos individuais pelos filósofos e autores chaves: Agamben, Rawls e Foucault. A partir disso, os objetivos consistem: buscar associação do pensar, desde a bioética, a quarentena, refletir sobre os interesses coletivos e a liberdade individual e compreender os conflitos dos elementos imbricados, no uso da quarentena humana, em sua complexidade na realidade.

Palavras-chave: Quarentena. Direitos Coletivos. Direitos Individuais. Estado de Exceção.

\footnotetext{
${ }^{1}$ Graduada em enfermagem pela Faculdade Associadas de Ariquemes (FAAr) e especialista em Docência do Ensino Superior pelas Faculdades Integradas Aparício Carvalho (FIMCA). E-mail: lorena_roas@hotmail.com.
} 
ABSTRACT: This research aims to study the bioethical aspects related to the social isolation in the pandemic and, its relevance in the present time between the collective and individual interests. The current pandemic of the new coronavirus has generated numerous questions about technical, ethical, moral, legal and social aspects involved in decisionmaking involving the health measures adopted by the democratic government. The use of human quarantine as an emergency health action in the fight against severe acute respiratory syndrome (SARS) at the beginning of the millennium significantly marked public health, opening a new field of discussions regarding the limits between protecting the community and reducing the right to autonomy and freedom of people or groups within a society. Paradoxically, he divided the opinion of experts between the effectiveness of the method and the legal and ethical aspects involved during its application. The present work will be based on the description and analysis of the human quarantine, from the perspective of bioethics through bibliographic review, on the description of its use today, on the possible risks that this measure represents to human autonomy, freedom and dignity. The bioethical aspects were raised in the search for justification to verify the adequacy or not of the decisions taken. It is important to clarify that bioethics can use several models to carry out this reflection, with emphasis on four major theoretical references: virtues, principles, rights and otherness. Its definition and concept were highlighted in the research through Potter's thoughts, as well as the discussion about the state of exception, the applicability of quarantine and the overlapping of collective interests in individual ones by the philosophers and key authors:Agamben, Rawls and Foucault . Based on this, the objectives are: to seek an association of thinking, from bioethics, to quarantine, to reflect on collective interests and individual freedom, and to understand the conflicts of the overlapping elements, in the use of human quarantine, in its complexity in reality.

Keywords: Quarantine. Collective Rights. Individual Rights. Exception status.

\section{INTRODUÇÃO}

A atual pandemia do novo coronavírus ocasionou muitos problemas e questionamentos técnicos, éticos, legais e de participação social. Principalmente, em questão da medida de saúde pública "quarentena", destinada a conter surtos epidêmicos ou a evitar que um determinado agente infeccioso atinja um território ou grupo social.

No Brasil, no dia 3 de fevereiro de 2020, o Ministério da Saúde declarou emergência de saúde pública de importância nacional, através da portaria $\mathrm{n}^{\mathrm{O}} \mathrm{I} 88$, devido ao novo coronavírus ser infectado por humanos, o nível de risco é 3 (SARS-CoV-2). O objetivo da ação era aprovar medidas administrativas, ter mais agilidade para que o país começasse a se preparar para o enfrentamento de uma pandemia, embora nenhum caso confirmado tenha sido registrado na época. Em 26 de fevereiro, o Ministério da Saúde notificou o Brasil sobre o primeiro caso de nova infecção por coronavírus em São Paulo e, desde então, todos os países permaneceram vigilantes. As medidas de higiene das mãos e etiqueta respiratória foram reforçadas. No entanto, a doença progrediu rapidamente, entrando na comunidade ou espalhando casos de forma sustentável em menos de 30 dias. 
Tratando-se de uma situação de interesse público e de responsabilidade geral, a estrutura relacionada com a administração pública é colocada em primeiro lugar na gestão, embora também estejam envolvidos outros setores como o mercado, a religião, a ciência e as instituições da sociedade civil. Os cidadãos também têm um papel fundamental, podem ser vítimas de doenças e assumir responsabilidades cívicas e morais pelas medidas de prevenção e controle das doenças.

Medidas clássicas de saúde pública, como aumento da higiene e redução do contato interpessoal provaram ser as mais eficazes no combate ao COVID-19. Entre essas práticas, encontram-se a quarentena e o isolamento social, que têm como objetivo impedir que doenças se espalhem para os humanos, interrompendo a transmissão do vírus. Embora as atividades para reduzir os contatos interpessoais datem da Grécia antiga, elas nunca foram usadas em tão grande escala. Intervenções de saúde pública como as descritas, limitam os movimentos e o contato entre as pessoas, produzem complexos problemas éticos, jurídicos, sociais e econômicos. Se por um lado são necessárias como medida de proteção à saúde coletiva, embora, podem prejudicar a saúde individual.

Este fato óbvio causou o primeiro e de longe o mais importante dilema relacionado ao isolamento: ele leva a uma violação substancial da liberdade pessoal - portanto, apenas de sua base ética. Em outras palavras, para ganhar esperança ética, o isolamento deve proteger efetivamente a saúde pública. Mas isso é eficaz? O isolamento é eficaz? Caso contrário, vale a pena discutir quaisquer ideias restantes sobre como justificar, eticamente, a quarentena.

Nesse contexto, o trabalho direciona aos seguintes questionamentos: Os interesses coletivos e os interesses individuais possuem o mesmo tipo de importância? Quem deve prevalecer, o interesse coletivo ou a liberdade individual? Por fim, há de fato diferenças consistentes entre interesses coletivos e interesses individuais? $O$ presente artigo tem intuito de abordar os aspectos bioéticos frente aos desafios dos governos democráticos em termos de controle e medidas de saúde pública, para enfrentar a contaminação massiva da população, excepcionalmente, durante uma pandemia.

\section{O novo Corona vírus}

Em janeiro de 2020, a Organização Mundial da Saúde (OMS) iniciou uma discussão sobre treinamento de emergências de saúde pública internacional, devido a descoberta em dezembro do ano anterior, do novo coronavírus na cidade de Wuhan, na China. Em ir de março de 2020, A COVID-ı, doença causada pelo vírus, foi declarada "pandemia" pela Organização Mundial da Saúde, o que significa que foi registrada a prevalência de doenças infecciosas. No Brasil, o primeiro caso COVID-19 ocorreu no dia 26 fevereiro de 2020. Em junho do mesmo ano, o país confirmou 600 mil casos confirmados. Além de casos assintomáticos e não notificados, há 33.000 mortes (SANTOS, 2020b).

Em um contexto histórico, trata-se de um vírus isolado pela primeira vez em $1937 \mathrm{e}$ em 1965 descrito como coronavírus, recebeu esse nome, porque era microscopicamente, semelhante a coroa dentária. Entre 2002 e 2003, a Organização Mundial da Saúde relatou 774 mortes por Síndrome Respiratória Aguda Grave (Sars-CoV), 858 mortes confirmadas em 2012 Ambos são causados pela Síndrome Respiratória do Oriente Médio (Mers-CoV), na Arábia Saudita complicações causadas por membros da família dos coronavírus. E, em 2019 
princípio de 2020, oito anos depois, o mundo enfrenta o vírus de RNA mutante, especialmente na forma assintomática, como uma infecção emergente, seus sintomas são mais leves do que Sars-CoV e MersCoV, mas têm maior capacidade de transmissão, impactando consideravelmente o sistema de saúde (OLIVEIRA; LUCAS; IQUIAPAZA, 2020).

Neste caso, a OMS declarou a pandemia Covid-I9 em ir de março de 2020, época em que medidas básicas de prevenção e resposta foram formuladas, incluindo: a lavagem das mãos com água e sabão sempre que possível e usar álcool em gel na ausência de contato com água e sabão. Enfatizaram, evitar tocar nos olhos e nariz, proteger a boca ao tossir e espirrar, adotando assim a etiqueta de respiração, utilizando os cotovelos dobrados ou lenços descartáveis. Além disso, a OMS indicou manter distância social (pelo menos i metro) e evitar reuniões, e usar uma máscara em caso de gripe ou infecção por Covid-ı9 ou assistência médica para pacientes suspeitos / infectados (WHO, 2020).

\section{As medidas de saúde pública}

A saúde pública considerada: "a saúde é a manifestação do mais alto grau de felicidade que os indivíduos e as comunidades podem alcançar" e tem como objetivo o processo de saúde da comunidade, observando as suas condições biológicas, psicológicas, social e de saúde (FORTES; ZOBOLI, 2009).

A saúde pública segundo Santos (2014), pode ser compreendida como mais ou menos complexa, pois é afetada pelo setor social, seja para promoção da saúde ou prevenção de doenças. No entanto, o termo é um tanto incerto ao fornecer condições e sustentar a vida e acusar o "estilo de vida sem saúde". Existe um dilema entre a autonomia de intervenção no direito de existir saúde e vulnerabilidade na manutenção de um ambiente social saudável. Nesta vulnerabilidade, o indivíduo é afetado pelas condições de vida, tornando-o mais vulnerável a sofrer de doenças, especialmente, epidemias.

A ação sanitária que implica no controle de fronteira é uma política nacional cujo objetivo é transmitir ideias protetivas em um ambiente popular, levando em consideração a necessidade implacável de segurança. As medidas tomadas para enfrentar o risco de epidemias são a quarentena, e o isolamento e a última medida é a detenção de pessoas em tratamento em meio hospital. Sob a orientação de uma comissão composta por vários especialistas, na área da saúde, as medidas de monitorização são muito importantes no processo de seguimento da regulamentação e da análise de risco e tomada de medidas ao longo da duração da doença, de forma a produzir respostas mais eficazes em termos de medidas. A ética segue princípios deontológicos. Não há comitê de ética ou qualquer forma de participação de outros setores da sociedade (BARBERA et al., 20oI).

Como medida de saúde, sua ação é quase inteiramente razoável, pois envolve a proteção da vida, objetivo principal da pesquisa bioética, pois a vida é o maior valor do ser humano, portanto, a "Declaração Universal da Bioética e Direitos Humanos" (DUBDH), a considera indispensável. Sobre questões sociais, as medidas de quarentena humana reproduzem a tomada de decisão em ações administrativas, com elevadas despesas de gastos públicos em situações facilmente contornáveis se o foco for o âmbito administrativo. No âmbito legal, sua ação pode ocultar o poder sitiante do Estado frente à liberdade de 
indivíduos ou pequenos grupos. Em outro sentindo, pode espelhar uma forma latente de poder e controle sobre a vida dos cidadãos, já vistos na história na forma de regimes governamentais autoritários (SANTOS, 2014).

\subsection{A quarentena humana}

A palavra quarentena vem [do frag. quarantaine] derivado de quadraginata e a palavra italiana quarenta, atribuída o período de quarentena de 40 dias para passageiros e cargas em navios. Era imposta pelas autoridades portuárias sobre os passageiros ou tripulantes, na qual suspeitasse de doenças infecciosas, impondo a incomunicabilidade a bordo dos navios, condicionados a permanecerem sem atracar (SANTOS; NASCIMENTO, 2014).

Segundo Wynia (2007) embora os termos "isolamento" e "quarentena" sejam frequentemente usados de forma intercambiável, eles não são os mesmos. Quarentena refere-se ao ato de isolar ou restringir pessoas saudáveis que foram ou podem estar infectadas com doenças infecciosas. Isolamento refere-se ao isolamento de pessoas que estão doentes, presumivelmente ou sabidamente infectadas. $\mathrm{O}$ isolamento é muito menos controverso e tem sido usado por muito tempo para pacientes hospitalizados com tuberculose, catapora, meningite bacteriana e outras infecções.

$\mathrm{O}$ valor de 40 dias pertencente ao nome do exercício - quarentena - tem origens históricas na China antiga. Nos estágios iniciais da implementação das vacinas antivirais, quando as crostas extraídas das pessoas infectadas por varíola, foram observadas que permaneciam infectadas por cerca de 40 dias, sendo apenas 20 dias no verão 18 no inverno. Essa observação cotidiana orienta as mais diversas práticas culturais, cujo objetivo é purificar ou conter a propagação de doenças infecciosas (KILWEIN, 1995).

Como uma das medidas para prevenir a disseminação do novo coronavírus, a OMS recomenda isolamento social para todas as pessoas que podem ficar em casa, ou seja, que não trabalham na indústria de serviços considerados essenciais. Em I8 de março, Santa Catarina foi o primeiro estado do Brasil a emitir uma ordem de quarentena, onde comércios, estádios, templos e igrejas, transporte público, parques e locais públicos, foram proibidos. Essas medidas foram implantadas de forma mais ou menos flexíveis, em vários outros Estados e municípios (SANTOS, 202ob).

\subsection{Reflexões Bio (éticas) sobre o contexto da pandemia}

Segundo Potter, pioneiro de termos e conceitos de disciplina de bioética, amor e promoção da vida (com base no conhecimento biológico), e essas ações não só promovem sua preservação, mas também promovem seu uso no mais alto nível e qualidade. De acordo com a definição, uma pessoa é uma criatura, então ela está automaticamente vinculada à bioética, ou seja, ela é primeiro inserida no objetivo da disciplina. Potter propôs que a bioética é uma ponte entre a ciência e a ética. $O$ instinto de Potter em seu artigo atualizado sobre os requisitos bioéticos de Fritz Jahr insistia que, em uma civilização decente e sustentável, a sobrevivência da maioria dos humanos depende do desenvolvimento e da manutenção do sistema ético (DEL RÍO; WEBER, 2009). 
O risco da liberdade e da autonomia humanas é um dos campos que impulsiona as pesquisas no campo da bioética, pois representa o campo de fronteira mais recente em que potenciais problemas (sejam novos ou persistentes, visíveis ou invisíveis). As discussões apontam que os riscos da bioética são como medidas de quarentena humana: embora não tenham sido comprovadas, cientificamente, como eficazes, têm sido aceitos sem crítica no ambiente epidêmico para transmitir as ideias de proteção e segurança. As leis federais dos Estados Unidos e de outros países / regiões centrais autorizam a cooperação entre o governo federal e os estados para planejar, treinar e prevenir epidemias e outras emergências de saúde. Durante a quarentena contínua de seres humanos, as ações de vigilância durante a duração da doença são muito óbvias, geralmente arbitrárias e seguem padrões internacionais. Tendo em vista a vulnerabilidade das pessoas cujos direitos foram privados da vida nua, não há menção à participação de comitês de ética ou quaisquer outras formas de participação de outros setores da sociedade (CENTRON; LANDWIRTH, 2005; AGAMBEN, 2004).

Beauchamp e Childress (1978) trazem em seu livro "Princípios de Ética Biomédica" os princípios utilizados na bioética, como recomendação de serem utilizados como deveres prima facie. Segundo os autores prima facie são obrigações que devem ser cumpridas, a menos que entrem em conflito com outras obrigações de mesma escala ou maior sob certas circunstâncias. Dessa forma, em caso de conflito, obrigações ostensivas podem ser consideradas ou priorizadas. $\mathrm{Na}$ bioética, são utilizados basicamente três princípios: beneficência, respeito às Pessoas e Justiça. Beauchamp e Childress desdobram o princípio da Beneficência e Não Maleficência e reduziram o Respeito às Pessoas a Autonomia. Em uma situação de pandemia, a Beneficência, entendida como o dever prima facie de fazer o bem e evitar o mal, é primordial para os profissionais de saúde. A justiça, como dever de distribuir, adequadamente, de forma não discriminatória, os bens entre os membros da sociedade, assim como de reconhecer e proteger, adicionalmente, os grupos ou pessoas vulneráveis, é fundamental para os gestores no desempenho de suas tarefas. $O$ respeito às pessoas, englobando o dever de veracidade, de reconhecimento da voluntariedade, da autodeterminação e da confidencialidade, é dever de todos.

\section{Direitos individuais e coletivos na saúde pública}

Dentro da constituição brasileira há dois tipos de estado de exceção: o de defesa, "que restaura e preserva o mais rápido, a ordem pública em locais restritos e determinados ou que estão ameaçados por restrição física severa iminente ou um grande desastre na natureza" e o de sítio, em caso de "grave repercussão nacional ou ocorrência de fatos que comprovem a ineficácia de medida tomada durante o estado de defesa" ou de "declaração de estado de guerra ou resposta a agressão armada estrangeira”. (VENTURA, 2010).

Sob o prisma do Direito, onde se lê pandemia, leia-se provável restrição das liberdades fundamentais. A gramática da vigilância epidemiológica compreende a quarentena, a limitação ou interdição de viagens, o recrudescimento do controle fronteiriço ou mesmo o fechamento de fronteiras, a imposição de terapias, a restrição ou supressão de reuniões públicas, a vacinação obrigatória, ou até ingerências no modo como se realizam os funerais. Além das interdições mais 
visíveis, na cotidiana gestão da escassez que toca aos sistemas de saúde dos países periféricos, a política pública a conduzir uma urgência sanitária traz em seu bojo complexas decisões (AGAMBEN, 2007, p.149).

Em Homo sacer II, Agamben define a exceção como "o dispositivo original graças ao qual o direito refere-se à vida e a inclui em si por meio de sua própria suspensão" (AGAMBEN, 2004, p. 12). O termo dispositivo, herdado do léxico foucaultiano, designa, por sua vez, discursos, instituições, edifícios, proposições filosóficas e medidas, cuja função estratégica é capturar e governar a vida: "a função dos dispositivos é, precisamente, a de capturar o vivente, dando lugar, por meio dessa captura, aos processos de subjetivação e dessubjetivação" (CASTRO, 2013, p. 164). Como dispositivo, a exceção designa um conjunto de medidas adotadas, constitucionalmente, com a função de capturar a vida humana por meio da suspensão do ordenamento jurídico - isto é, por meio da própria suspensão da lei.

$\mathrm{O}$ arcabouço dos direitos humanos estabelece garantias individuais e coletivas e é utilizado na Constituição Brasileira de 1988 e em alguns documentos internacionais, como a Declaração Universal de Bioética e Direitos Humanos. Os direitos individuais incluem vida, privacidade, liberdade e não discriminação. Todos esses direitos devem ser preservados, mas em circunstâncias especiais como uma pandemia, eles podem ser substituídos por direitos coletivos, como saúde, educação e assistência social, que são garantia de todos. Para garantir a saúde das pessoas em situação de risco, é um benefício maior que elas possam ficar isoladas, o que impõe restrições claras à sua liberdade. A troca obrigatória de informações por parte dos pacientes relacionadas à doença não deve ser entendida como invasão de privacidade, pois esses dados repassados às autoridades de saúde para fins de controle epidemiológico devem ser protegidos. Isso é essencial para manter uma relação médico-paciente adequada com base na relação entre as obrigações de confidencialidade do médico e o direito do paciente à privacidade (GOLDIM, 2009).

O Estado Democrático suspende a autonomia da vida política e purificam a estrutura social, sacrificando a chamada liberdade individual. Portanto, a política da vida - biopolítica -coincide com a política da morte-política, cujo Foucault esclareceu o paradigma: "deixe-o sobreviver, deixe-o morrer" - a Tanatopolítica. Na Tanatopolítica, as formas de vida não produtivas são "descartadas" às custas das formas de vida produtivas. A observação de Agamben e Esposito mostram que na política contemporânea já não tem significado a distinção entre "comunidade" e "imunidade" romana, mas sim uma fusão epistemológica na qual se formam as comunidades, e não mais pela comunes, ou seja, pessoas com obrigações comuns, mas pessoas com imunidade, ou seja, pessoas com imunidade biológica e social comum. Trata-se, portanto, do surgimento de uma sociedade higienizante, que em sua assepsia política, toma o contato humano como risco de exposição à morte. As teses filosóficas de Foucault, de Agamben, de Esposito e de Preciado revelam, portanto, que a política moderna e a contemporânea se constituem na interseção de três formatos de poder: "biopolítica", "tanatopolítica" e "política imunitária". Tais conceitos, entretanto, constituem o núcleo do "estado de exceção" contemporâneo, sendo a exceção, por sua vez, a "normalização" do insuportável paradoxo da biotanatopolítica (BUCHARD, 2020).

Nesse contexto de ações coletivas e individuais, assiste-se a manifestações de tensão ética, como conflitos causados pelos seguintes motivos: valores e objetivos diferenciados, 
informações limitadas e dispersas, necessidades múltiplas e escassez de recursos. Essas tensões fazem com que os dilemas morais apareçam mais claramente, o que torna o processo de tomada de decisão moral (um processo de tomada de decisão que pode beneficiar ou prejudicar outras pessoas) mais complicado. Além disso, podem influenciar políticas públicas e ações governamentais na gestão de pandemias (SANTOS, 2020a).

\section{Um pensar filosófico nos dilemas da quarentena}

A circunstância bioética levou Lin e Anderson-Shaw (2009) a discutirem e propor um modelo de tomada de decisão em situações pandêmicas com base em um modelo ético principialista e utilitarista, ressaltando os princípios da benevolência, justiça distributiva e o princípio da utilidade. Segundo os autores, em situações de desastres de grande escala, como epidemias ou pandemias, os indivíduos são tratados no âmbito da saúde pública, por isso é necessário manter o equilíbrio entre o indivíduo e coletivo. No ambiente pandêmico, a justiça é distributiva, e os autores acrescentam que justiça e bondade juntas garantem a distribuição justa de recursos escassos. De acordo com o princípio da utilidade, deve-se sempre escolher o maior benefício para o maior número de pessoas.

Rawls propôs que as pessoas deveriam ser capazes de pensar no conceito de justiça pública, não em filosofia, moralidade ou dogma religioso. Essa maneira de pensar sobre a justiça só é possível por meio do que os filósofos americanos chamam de "consenso sobreposto". Este conceito mostra com precisão o significado do nome: um consenso que cobre as diferenças individuais, sejam diferenças filosóficas, morais ou religiosas. Cerca de cinquenta anos atrás, John Rawls lançava seu clássico A Theory of Justice. Na obra, o filósofo americano aborda o problema da justiça distributiva (a distribuição socialmente justa de bens em uma sociedade) tendo como base tanto uma revisão da filosofia kantiana, como uma variante da teoria convencional dos contratos sociais. Pode-se encontrar, no livro, uma resposta bastante razoável às questões apresentadas no início e que envolvem a noção de justiça social (RAWLS, 2008).

Para dar respostas a esses dilemas, Rawls propôs um experimento psicológico que envolve partir de uma "posição primitiva" sobre a sociedade e, em seguida, perguntar às pessoas como elas irão estabelecer a escolha feita por trás do que ele chama "véu da ignorância". Os experimentos psicológicos envolvem as seguintes questões: Se as pessoas se desconhece como nasceriam (classe social, gênero, raça, etc.), o esperariam da sociedade para a justiça social? $O$ véu da ignorância impõe uma série de restrições de conhecimento às pessoas. Uma vez que as pessoas não soubessem nada sobre si mesmas (ou suas condições sociais), Rawls acredita que as coisas que são consideradas "mais justas" devem ser escolhidas da perspectiva de interesses mais gerais. Ou seja, para uma profilaxia de possível tratamento injusto, as pessoas fariam sugestões para o sucesso geral da sociedade e levarão a um nível bom e eficaz de equidade, justiça e liberdade (RAWLS, 2008).

Diante do dilema que se enfrenta hoje, e com base na teoria de Rawls, pode-se perguntar: Se o indivíduo se desconhece a que classe social pertenceria ao nascer, que política social iria defender (ou rejeitar) contra o COVID-I9? Se fosse desconhecido (por exemplo) se iria cair na categoria de risco, ou se encaixaria como empregados, contratados ou grandes 
empresários, qual posição escolheria na política de isolamento? Para Rawls, a garantia das necessidades básicas formará a base da justiça social, porque não entenderias as condições de vida.

$\mathrm{Na}$ verdade, o livro de Rawls é considerado um dos argumentos filosóficos mais claros para os arranjos institucionais das democracias liberais. Vários líderes políticos e religiosos no mundo têm abordado os dilemas apresentados pelo novo coronavírus sob um ponto de vista muito próximo ao que foi proposto pelo filósofo americano, tendo a equidade como critério de justiça social para as ações governamentais relacionadas à pandemia (MULINARI, 2020).

Seguindo esse caminho de discussão, Foucault fala pela primeira vez em biopolítica em uma conferência realizada no Brasil em 1974 sobre, O Nascimento da medicina social, entretanto, um esforço conceitual em relação à biopolítica só aparece de fato no curso, em defesa da sociedade. Neste, Foucault menciona a biopolítica, numa guinada algo repentina e abrupta, para qualificar a sua discussão sobre raça e racismo. A definição do racismo moderno é surgir num momento de grande dominância do paradigma biopolítico, do fazer viver e deixar morrer. No racismo moderno, refletido por Foucault (1999) estrutura a biopolítica da população tendo como ponto básico a configuração compulsiva de um corte entre o que é saudável e o que é doentio, entre o normal e o patológico e, consequentemente, entre o que deve viver e o que deve morrer.

Para Sotiris (2020), em uma interpretação utópica da biopolítica, as medidas disciplinares e regulatórias tomadas para conter o novo coronavírus não apenas expressam "um sentimento permanente de medo pessoal que pode quebrar qualquer sentimento de coesão social", mas o mais importante " A ideia de esforço coletivo, coordenação e unidade em uma luta comum é tão importante quanto a intervenção médica neste tipo de incidente médico emergencial. Portanto, a "possibilidade de uma biopolítica democrática" relacionada na "democratização do conhecimento" abrirá caminho para "um processo de tomada de decisão coletiva baseado no conhecimento e na compreensão, e não apenas na autoridade de especialistas".

\footnotetext{
Na obra Homo sacer II, Agamben retoma a tese de Benjamin para concluir que, se o estado de exceção em que vivemos é a regra, isso ocorre porque as políticas modernas e contemporâneas funcionam sob o paradigma da suspensão e revogação dos direitos humanos e cívicos, como estratégia para assegurar a soberania do Estado Democrático (AGAMBEN, 2004, p. 2I).
}

Em nenhum momento, Agamben abordou como um problema de saúde pública, a pandemia, e que a mesma teria sido inventada para restringir liberdades e manter o estado de exceção como paradigma normal de governo. O que permite concluir que, para o autor, a atual pandemia serve de oportunidade para a normalização do paradigma da exceção como forma de governo nas democracias contemporâneas e de ocasião para a realização plena do regime da biopolítica. 


\section{Considerações Finais}

As reflexões presentes nesse artigo, podem ser resumidas em dois aspectos: mostrar situações emergentes constantemente que exigi um discernimento moral na prática diária e enfatizaram que é impossível desenvolver um conjunto simples de regras para resolver esses problemas.

Como foi abordado, uma bioética adequada à saúde pública e baseada no princípio da proteção, restaurando o sentido considerado como uma ética primitiva, e pertencente a uma importante tradição socialmente (sociedade do século XIX). A tentativa de restaurar o “estado mínimo" é um papel relevante do estado moderno, podendo-se argumentar que só é legal se tiver a capacidade de fornecer proteção adequada aos seus cidadãos, mesmo que estes tomem decisões por bons motivos. De fato, neste caso, os interesses dos bens públicos podem legitimar medidas coercitivas que restringem a liberdade individual e, caso não sejam observadas, podem acarretar sanções ao infrator. Em suma, com base na prioridade dos direitos sociais sobre os indivíduos, a proteção da saúde pública legitima certas formas de restrição ao exercício da autonomia pessoal.

A característica comum da prática de ação em saúde e da prática de pesquisa é que existem muitas situações que envolvem escolhas éticas. Portanto, não se trata de um conjunto de decisões formais, pois proporcionará aos profissionais e pesquisadores meios suficientes para garantir a escolha certa. Como afirmado no início desses pensamentos, não pode haver nenhum mecanismo e meio teoricamente disponível para provar a verdade no nível prático da vida. A escolha correta está sujeita a inúmeras proibições, entre as quais, desde que tal escolha inclua o objetivo de alcançar interesses comuns no objetivo, deve evidenciar os requisitos morais.

\section{Referências Bibliográficas}

AGAMBEN, Giorgio. Estado de exceção: homo sacer II, I. Tradução: Iraci D. Poleti. $2^{\underline{a}}$ ed. São Paulo: Boitempo, 2004.

AGAMBEN, Giorgio. Homo Sacer: o poder soberano e a vida nua. Belo Horizonte: Editora UFMG, 2007 .

BARBERA, Joseph et al. Largescale quarantine following biological terrorism in the Unitet Satates. Journal of the American Medical Association, v. 286, n. 21, pág. 2711-2717, 2001.

BEAUCHAMP Tom, CHILDRESS James. The Principles of biomedical ethics. I ed. New York: Oxford; 1978.

BUCHARD, Alan Barbosa. Estado de exceção e emergência sanitária: Giorgio Agamben sobre a pandemia por coronavírus. Investigação Filosófica, v. II, n. 2, p. 37-53, 2020.

CASTRO, E. Introdução a Giorgio Agamben: uma arqueologia da potência. Trad. Beatriz de Almeida Magalhães. I. reimp. Belo Horizonte: Autêntica Editora, 2013. 
CETRON, Martin; LANDWIRTH, Julius. Public health and ethical considerations in planning for quarantine. The Yale journal of biology and medicine, v. 78, n. 5, p. 329, 2005.

DEL RÍO, Asunción Álvarez; WEBER, Paulina Rivero. El desafío de la bioética. México: Editorial Fondo de Cultura Económica, p. II-28, 2009.

FORTES, Paulo Antônio Carvalho; ZOBOLI, Elma Lourdes Campos Pavone. Bioética e Saúde pública. São Paulo: Ed. Loyola. 2009.

FOUCAULT, Michel. Em Defesa da Sociedade. São Paulo: Martins Fontes, I999.

GOLDIM, José Roberto. Bioética e pandemia de influenza. Revista HCPA. Porto Alegre. Vol. 29, n. 2, p. 16I-166, 2009.

KILWEIN, John. Some historical comments on quarantine: part two. J Clin Pharm Ther. 1995 [cited 2013 Nov 29];20(5):249-252.

LIN, Janet; ANDERSON-SHAW, Lisa. Rationing of resources: ethical issues in disasters and epidemic situations. Prehospital and disaster medicine, v. 24, n. 3, p. 215-221, 2009.

MULINARI, Filicio. Ética e Justiça social em tempos de pandemia. Early Draft [Versão inicial]. Maio de 2020 .

OLIVEIRA, Adriana Cristina de.; LUCAS, Thabata Coaglio; IQUIAPAZA, Robert Aldo. O que a pandemia da COVID-ıg tem nos ensinado sobre adoção de medidas de precaução? Texto \& Contexto Enfermagem 2020, v.29.

RAWLS, J. Uma Teoria da Justiça. 3. ed. Tradução de Jussara Simões. São Paulo: Martins Fontes, 2008. 764p.

SANTOS, Boaventura de Sousa. La cruel pedagogía del virus. Ediciones AKAL, $2020 a$. , Iris Almeida dos. Conflitos bioéticos na quarentena humana. Dissertação, Brasília: 2014.

Iris Almeida dos; NASCIMENTO, Wanderson Flor do. As medidas de quarentena humana na saúde pública: aspectos bioéticos. Revista Bioethikos, São Paulo, v. 8, n. 2, p. 174-185, 2014.

Laís Silveira. Dilemas morais da gestão pública brasileira no enfrentamento da pandemia do novo coronavírus. Revista de Administração Pública, v. 54, n. 4, p. 909-922, 202ob. 
SOTIRIS, Panagiotis. Coronavirus contra Agamben. Por una biopolítica popular. Uninómada Sur, 2020.

VENTURA, Deisy. Pandemias e estado de exceção. In: Anais do VII Congresso Internacional de Direito da USJT. 2010. p. 4I-56.

WHO. World Health Organization. Rational use of personal protective equipment (PPE) for coronavirus disease (COVID-19): interim guidance [Internet]. Geneva; 2020 [cited 2020 Mar 23].

WYNIA, Matthew K. Ethics and public health emergencies: restrictions on liberty. The American Journal of Bioethics. 2007; 7 (2):1-5.

ZIZEK, Slavoj. PANDEMIC!: Covid-ı9 Shakes the World. John Wiley \& Sons, 2020. 